\title{
The role of Gliadel wafers in the treatment of newly diagnosed GBM: a meta-analysis
}

This article was published in the following Dove Press journal:

Drug Design, Development and Therapy

29 June 2015

Number of times this article has been viewed

\section{Wei-kang Xing' \\ Chuan Shao ${ }^{2}$ \\ Zhen-yu Qi' \\ Chao Yang' \\ Zhong Wang'}

'Department of Neurosurgery, The First Affiliated Hospital of Soochow University, Suzhou, Jiangsu, ${ }^{2}$ Department of Neurosurgery, The Second Clinical Medical College of North Sichuan Medical College, Nanchong, Sichuan, People's Republic of China
Correspondence: Zhen-yu Qi

Department of Neurosurgery, The First Affiliated Hospital of Soochow University, I88 Shizi Street, Suzhou, Jiangsu 215006, People's Republic of China Email qizhenyu@suda.edu.cn
Background: Standard treatment for high-grade glioma (HGG) includes surgery followed by radiotherapy and/or chemotherapy. Insertion of carmustine wafers into the resection cavity as a treatment for malignant glioma is currently a controversial topic among neurosurgeons. Our meta-analysis focused on whether carmustine wafer treatment could significantly benefit the survival of patients with newly diagnosed glioblastoma multiforme (GBM).

Method: We searched the PubMed and Web of Science databases without any restrictions on language using the keywords "Gliadel wafers", "carmustine wafers", "BCNU wafers", or "interstitial chemotherapy" in newly diagnosed GBM for the period from January 1990 to March 2015. Randomized controlled trials (RCTs) and cohort studies/clinical trials that compared treatments designed with and without carmustine wafers and which reported overall survival or hazard ratio (HR) or survival curves were included in this study. Moreover, the statistical analysis was conducted by the STATA 12.0 software.

Results: Six studies including two RCTs and four cohort studies, enrolling a total of 513 patients (223 with and 290 without carmustine wafers), matched the selection criteria. Carmustine wafers showed a strong advantage when pooling all the included studies ( $\mathrm{HR}=0.63,95 \%$ confidence interval $(\mathrm{CI})=0.49-0.81 ; P=0.019)$. However, the two RCTs did not show a statistical increase in survival in the group with carmustine wafer compared to the group without it ( $\mathrm{HR}=0.51$, $95 \% \mathrm{CI}=0.18-1.41 ; P=0.426$ ), while the cohort studies demonstrated a significant survival increase $(\mathrm{HR}=0.59,95 \% \mathrm{CI}=0.44-0.79 ; P<0.0001)$.

Conclusion: Carmustine-impregnated wafers play a significant role in improving survival when used for patients with newly diagnosed GBM. More studies should be designed for newly diagnosed GBM in the future.

Keywords: glioblastoma, carmustine wafers, meta-analysis, safety, efficacy, chemotherapy, drug implants, prognosis

\section{Introduction}

Glioma is the most common type of primary brain tumors. ${ }^{1}$ Gliomas are graded as I to IV based on the histological appearance by the World Health Organization. ${ }^{2}$ High-grade gliomas (HGGs) belong to grades III or IV, and the majority of the grade IV subtype is glioblastoma multiforme (GBM). GBM, with an approximate incidence of 10,000 cases in USA and 74,000 cases around the world every year, accounts for nearly $60 \%$ of primary brain tumors. ${ }^{3}$ The treatment of patients with malignant glioma, including surgery followed by radiotherapy and/or chemotherapy, has remained relatively unchanged for 30 years.

Gliadel ${ }^{\circledR}$ wafer, a biodegradable polymer containing $3.85 \%$ carmustine $(1,3$ bis[2-chloroethyl]-1-nitrosourea [BCNU]), is implanted in the resection cavity, delivering carmustine directly at the time of surgery. These wafers could supply a controlled release of $7.7 \mathrm{mg}$ BCNU for around 5 days. ${ }^{4} \mathrm{BCNU}$ may alkylate the nucleoprotein and interfere with the DNA synthesis and repair, and the carbonylation 
of nucleoprotein lysine residues can also decrease RNA and protein synthesis. ${ }^{5}$

Use of interstitial carmustine wafers is currently a topic of controversy among neurosurgeons. Westphal et $\mathrm{al}^{6}$ believed that local chemotherapy with carmustine wafers offers a survival benefit to patients with newly diagnosed GBM. Affronti et $\mathrm{al}^{7}$ also emphasized that the BCNU wafer therapy is well tolerated and has a survival benefit compared with radiation alone. However, De Bonis et $\mathrm{al}^{8}$ showed a different result that there was no significant improvement in the outcome by adding BCNU wafers to standard treatment. Moreover, they stated that the toxicity after Gliadel use was significantly higher, for patients with both newly diagnosed and recurrent glioblastoma. Currently, treatment with BCNU wafers has been excluded in some clinical trials of new chemotherapies because of the potential toxicities and lack of reliable survival statistics. ${ }^{9}$

Efficacy and safety of implantation of BCNU wafers in the resection cavity had been demonstrated in randomized controlled trials (RCTs) in patients with both newly diagnosed and recurrent malignant gliomas. ${ }^{6,10,11}$ A metaanalysis including these three RCTs reported that the survival in patients with newly diagnosed HGG was significantly increased with BCNU wafers compared to treatment with placebo (hazard ratio [HR] $=0.65,95 \%$ confidence interval $[\mathrm{CI}]=0.48-0.86 ; P=0.003)$, but not in patients with recurrent disease $(\mathrm{HR}=0.83,95 \% \mathrm{CI}=0.62-1.10 ; P=0.2) .{ }^{12}$ RCTs are still too few, and fortunately, there are many cohort studies that are also meaningful. Therefore, what we want to know is whether the BCNU wafer treatment could prolong the survival in patients with newly diagnosed GBM, focused on RCTs and cohort studies/clinical trials. It might provide a powerful proof to help clinicians in making a decision regarding using $\mathrm{BCNU}$ wafers to treat newly diagnosed GBM.

\section{Materials and methods Publication search}

We searched the PubMed and Web of Science databases, using the terms "(glioma OR glioblastoma multiforme OR malignant gliomas OR brain tumor OR brain cancer) AND (Gliadel wafers OR carmustine wafers OR BCNU wafers OR interstitial chemotherapy carmustine OR chemotherapy wafers)" for the period between January 1990 and March 2015. No language limitation was imposed in this study. The citations of identified articles were also filtered for additional studies. Original searches were conducted independently by two reviewers.

\section{Inclusion criteria}

Studies meeting all the following inclusion criteria were considered eligible: 1) an RCT or cohort study; 2) the comparison of treatment modes with and without carmustine wafers should be designed; 3 ) the overall survival (OS) or HR or survival curves should be reported in the study; 4) the study quality should be high enough.

\section{Assessment of methodological quality}

RCTs that got a score of 3.0 to 5.0 using the Jadad scale (ranging from 0 to 5), were considered to be of high quality. ${ }^{13}$ The Newcastle-Ottawa scale (NOS) was used to assess the quality of the included cohort studies. ${ }^{14}$ Studies assessed by NOS (score range from 0 to $9^{*}$ ) as having scores of $6^{*}$ or more were deemed to be of relatively higher quality.

\section{Data collection}

The essential information was extracted carefully and independently from each included study by two authors: the first author's name, year of publication, country of research, age range of participants, number of participants (with/without carmustine wafers), study design, median survival, HR of OS, and adverse events (AEs). The study authors were contacted if missing data were required in this article. Any disagreement was resolved by discussion.

\section{Statistical analysis}

Pooled HRs and 95\% CIs, forest plot, heterogeneity, publication bias, sensitivity analysis, and statistical association were analyzed using the STATA software version 12.0 (STATA Corporation, College Station, TX, USA). ${ }^{15}$

The HR was used as the measure of association among studies. We attempted to abstract the data required to estimate them from the survival curves if the HR and 95\% CI were not presented. ${ }^{16}$ Two subgroups were assigned when pooling the HRs by the design of study. In addition, the overall association among all the studies was studied using the forest plot. Heterogeneity between studies in subgroups and the overall heterogeneity for all studies included were evaluated by Cochran's Q statistic. The heterogeneity was considered to be significant when $P<0.05 .{ }^{17}$ The $I^{2}$ test with results ranging from $0 \%$ to $100 \%\left(I^{2}>50 \%\right.$, high heterogeneity; $I^{2}=25 \%-50 \%$, medium heterogeneity; $I^{2}<25 \%$, low heterogeneity) was used to better estimate the extent of heterogeneity. ${ }^{18}$ The random-effects model was used to pool HRs in this meta-analysis.

Sensitivity analysis was performed to show the influence of individual data sets on the pooled HRs by omitting one 
study at a time. Egger and Begg tests were also applied to assess the publication bias..$^{19,20}$

\section{Results}

\section{Results of the search}

A flow chart of the steps in choosing the included studies is shown in Figure 1. The search strategy identified 291 relevant articles screened in the PubMed and Web of Science databases. We excluded 256 unrelated themes and had 35 articles for detailed evaluation. Ten reviews were excluded from further analyses. ${ }^{12,21-29}$ Nineteen of the remaining 25 studies were excluded after reading the full texts. Thirteen of them were excluded because the data on comparison between groups with and without carmustine wafers in the studies were not valid or because there was no comparison in them. ${ }^{30-42}$ Because of the treatment bias, the survival comparison was not the aim of another study. ${ }^{43}$ Two articles $^{44,45}$ used the same experimental data from the study by Westphal et al. ${ }^{6}$ One study did not present the survival data and we could not contact the author using the email provided in his article. ${ }^{46}$ The study focusing on recurrent GBM was also excluded. ${ }^{47}$ Finally, seven studies were included in our research. ${ }^{6-8,10,48-50}$ Because the same RCT study by Westphal et $\mathrm{al}^{6,50}$ was reported in both 2003 and 2006, we included the latest follow-up study for further analysis. Thus, a total of six studies were included in this meta-analysis. ${ }^{7,8,10,48-50}$

\section{Included studies}

The characteristics and statistical information of the six included studies are described in Tables 1 and 2. Two RCTs and four cohort studies enrolling a total number of 513 patients ( 223 with and 290 without BCNU wafers) matched the selection criteria. Studies were researched in Italy, France, the USA, Finland, Norway, and Germany (Table 1).

In one of the two RCTs, Westphal et $\mathrm{al}^{6,50}$ showed a long-term follow-up of the same trial they conducted earlier. Median survival in patients treated with BCNU wafers and in placebo-treated patients was 13.8 months and 11.6 months $(P=0.08)$, respectively. Similar results of median survival from two other studies are shown in Table 2 .

The numbers of newly diagnosed GBM patients were 27 and 207, and the age ranged from 21 years to 72 years in the two RCTs. The effect size outcomes of the subgroup of newly diagnosed GBM shown by Westphal et al ${ }^{50}$ were $(\mathrm{HR}=0.78,95 \% \mathrm{CI}=0.58-1.05)$ and by Valtonen et $\mathrm{al}^{10}$ were $(\mathrm{HR}=0.27,95 \% \mathrm{CI}=0.10-0.71)$. The other four were all cohort studies having a main OS comparison of treatment with or without carmustine wafers. One of the four cohort studies showed only old people (age $>65$ years) with GBM. ${ }^{49}$ The other three studies had an age range from 16 years to 82 years. Results of effect size of the cohort studies were as

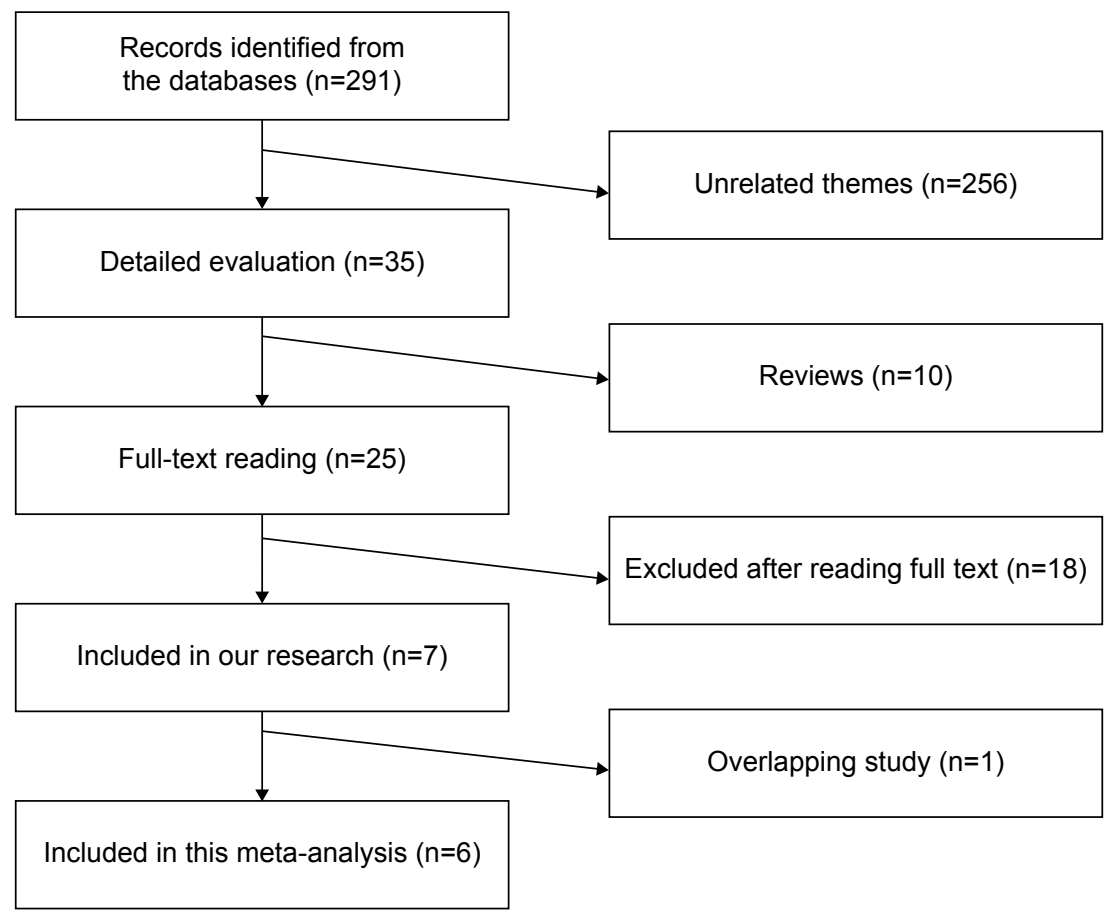

Figure I Flow chart of the studies chosen for this analysis. 
Table I Characteristics of included studies

\begin{tabular}{|c|c|c|c|c|c|c|}
\hline Study & $\begin{array}{l}\text { Country } \\
\text { of research }\end{array}$ & $\begin{array}{l}\text { Study } \\
\text { design }\end{array}$ & $\begin{array}{l}\text { Age } \\
\text { (years) }\end{array}$ & $\begin{array}{l}\text { Number of participants } \\
\text { (with/without carmustine) }\end{array}$ & $\begin{array}{l}\text { Maximum } \\
\text { follow-up (months) }\end{array}$ & $\begin{array}{l}\text { Quality } \\
\text { of studies }\end{array}$ \\
\hline De Bonis et $\mathrm{al}^{8}$ & Italy & Cohort & $35-76$ & $10 / 58$ & 24 & $\operatorname{NOS}\left(8^{*}\right)$ \\
\hline Noel et $\mathrm{al}^{48}$ & France & Cohort & $16-82$ & $20 / 16$ & 24 & $\operatorname{NOS}\left(7^{*}\right)$ \\
\hline Chaichana et $\mathrm{al}^{49}$ & USA & Cohort & $>65$ & $45 / 45$ & 44 & NOS (8*) \\
\hline Affronti et $\mathrm{al}^{7}$ & USA & Cohort & $24-76$ & $36 / 49$ & 39 & NOS (8*) \\
\hline Westphal et a ${ }^{50}$ & Germany & $\mathrm{RCT}$ & $21-72$ & $101 / 106$ & 39 & Jadad (3) \\
\hline Valtonen et $\mathrm{al}^{10}$ & Finland, Norway & RCT & $36-67$ & $11 / 16$ & 24 & Jadad (3) \\
\hline
\end{tabular}

Notes: *NOS scores; Cohort, cohort study; Jadad, Jadad scale.

Abbreviations: NOS, Newcastle-Ottawa scale; RCT, randomized controlled trial.

follows: Noel et $\mathrm{al}^{48}$ : HR $=0.72,95 \% \mathrm{CI}=0.29-1.79$ (estimated from the survival curve); De Bonis et $\mathrm{al}^{8}$ : HR $=0.40$, 95\% CI $=0.10-1.20$; Chaichana et $\mathrm{al}^{49}: \mathrm{HR}=0.55,95 \% \mathrm{CI}$ $=0.38-0.79$ (estimated from the survival curve); and Affronti et $\mathrm{al}^{7}: \mathrm{HR}=0.75,95 \% \mathrm{CI}=0.46-1.73$ (Table 2). The outcomes of assessment of methodological quality using NOS and Jadad scale are also shown in Table 1. Maximum follow-up duration of all the studies was 24 months.

\section{Stratifying analysis}

Figure 2 presents the forest plots of comparison between treatments with and without carmustine wafers in newly diagnosed GBM. The overall HR was 0.63 (95\% CI =0.49-0.81; $P=0.019)$, with low heterogeneity $\left(I^{2}=18.7 \%\right)$.

Stratifying by study design, the HR of all incorporated studies was $0.51(95 \% \mathrm{CI}=0.18-1.41 ; P=0.426)$, with high heterogeneity $\left(I^{2}=75.7 \%\right)$ for the RCTs, whereas in the cohort studies, the combined HR was $0.59(95 \%$ $\mathrm{CI}=0.44-0.79 ; P<0.0001)$, with low heterogeneity $\left(I^{2}=0.0 \%\right)$ (Figure 2$)$.

\section{Sensitivity analysis and publication bias}

In the sensitivity analysis, we evaluated the influence of each study on the overall results by omitting one single study at a time. No significant relation was found when omitting Westphal et $\mathrm{al}^{50}$ and Valtonen et $\mathrm{al}^{10}$ from the studies shown in Figure 3. The combined HRs were 0.554 $(95 \% \mathrm{CI}=0.418-0.734)$ for Westphal et $\mathrm{al}^{6}$ and $0.678(95 \%$ $\mathrm{CI}=0.550-0.835)$ for Valtonen et al. ${ }^{10}$

The results of $\operatorname{Begg}(P=0.260)$ and $\operatorname{Egger}(P=0.255)$ tests showed no significant bias. Moreover, we also found no obvious asymmetry from the Egger test (Figure 4), indicating that no evidence of publication bias was discovered.

\section{Adverse events}

Four of the six included studies reported AEs. The AE rates that Valtonen et $\mathrm{a}^{10}$ presented for BCNU and placebo wafers were $75 \%$ (12/16 [events/total]) and 55\% (6/11), respectively (nonsignificant). Westphal et $\mathrm{l}^{6,50}$ showed the AEs for Gliadel vs placebo as follows: brain edema (23/101 vs 19/106); seizure (33/101 vs 38/106); healing abnormality $(16 / 101$ vs $12 / 106)$; infection (5/101 vs $6 / 106)$; thrombosis $(18 / 101$ vs $17 / 106)$; and intracranial hypertension (9/101 vs 2/106). Intracranial hypertension was the only statistically significant complication $(P=0.019) .{ }^{6,50}$ In the study by Affronti et $\mathrm{al}^{7}$ complications (BCNU vs no BCNU) including infection (4/36 vs 4/49) and thrombosis (4/36 vs 3/49) were shown. However, De Bonis et $\mathrm{al}^{8}$ listed statistically significant AEs $(\mathrm{HR}=3.0,95 \% \mathrm{CI}=1.1-7.4 ; P=0.019)$ and implantation siterelated AEs $(\mathrm{HR}=5.6,95 \% \mathrm{CI}=2.0-16.0 ; P=0.001)$, which emphasized that toxicity with the use of Gliadel for patients with GBM was higher.

Table 2 Statistical information of included studies

\begin{tabular}{|c|c|c|c|c|c|c|}
\hline \multirow[t]{2}{*}{ Study } & \multicolumn{3}{|c|}{ Median survival (months) } & \multicolumn{3}{|c|}{ Overall survival } \\
\hline & With BCNU & Without BCNU & $\boldsymbol{P}$ & HR & $95 \% \mathrm{Cl}$ & $\boldsymbol{P}$ \\
\hline De Bonis et $\mathrm{al}^{8}$ & NR & NR & NR & 0.4 & $0.1-1.2$ & 0.15 \\
\hline Noel et $\mathrm{al}^{48}$ & NR & NR & NR & $0.72^{\mathrm{a}}$ & $0.29-1.79^{a}$ & NR \\
\hline Chaichana et $\mathrm{a}^{49}$ & 8.7 & 5.5 & 0.007 & $0.55^{\mathrm{a}}$ & $0.38-0.79^{a}$ & NR \\
\hline Affronti et $\mathrm{al}^{7}$ & NR & NR & NR & 0.75 & $0.46-1.73$ & 0.252 \\
\hline Westphal et al ${ }^{50}$ & 13.8 & 11.6 & 0.08 & 0.78 & $0.58-1.05$ & 0.10 \\
\hline Valtonen et $\mathrm{al}^{10}$ & 12.4 & 9.3 & 0.008 & 0.27 & $0.10-0.7 \mid$ & 0.008 \\
\hline
\end{tabular}

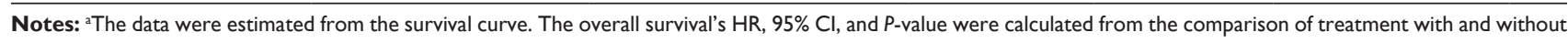
carmustine wafers.

Abbreviations: BCNU, I,3-bis[2-chloroethyl]-I-nitrosourea or carmustine wafers; Cl, confidence interval; HR, hazard ratio; NR, not reported; $P$, $P$-value. 


\begin{tabular}{|c|c|c|}
\hline Study ID & HR $(95 \% \mathrm{Cl})$ & $\%$ weight \\
\hline \multicolumn{3}{|l|}{1} \\
\hline Westphal et al ${ }^{50}$ & $0.78(0.58,1.05)$ & 39.63 \\
\hline Valtonen et $\mathrm{al}^{10}$ & $0.27(0.10,0.71)$ & 6.15 \\
\hline Subtotal $\left(P^{2}=75.7 \% ; P=0.042\right)$ & $0.51(0.18,1.41)$ & 45.78 \\
\hline \multicolumn{3}{|l|}{2} \\
\hline De Bonis et $\mathrm{al}^{8}$ & $0.40(0.10,1.20)$ & 3.93 \\
\hline Noel et $\mathrm{al}^{48}$ & $0.72(0.29,1.79)$ & 7.05 \\
\hline Chaichana et al ${ }^{49}$ & $0.55(0.38,0.79)$ & 30.81 \\
\hline Affronti et $\mathrm{al}^{7}$ & $0.75(0.46,1.73)$ & 12.43 \\
\hline Subtotal $(R=0.0 \% ; P=0.752)$ & $0.59(0.44,0.79)$ & 54.22 \\
\hline Overall $\left(I^{2}=18.7 \% ; P=0.292\right)$ & $0.63(0.49,0.81)$ & 100.00 \\
\hline $\begin{array}{r}1 \\
-1\end{array}$ & $\begin{array}{l}1 \\
10\end{array}$ & \\
\hline
\end{tabular}

Figure 2 Forest plot of comparison between treatments with and without carmustine wafers in newly diagnosed GBM. Note: Weights are from random-effects analysis.

Abbreviations: $\mathrm{Cl}$, confidence interval; GBM, glioblastoma multiforme; $\mathrm{HR}$, hazard ratio.

\section{Discussion}

GBM is one of the most malignant tumors in human beings. The standard treatment, surgery followed by radiotherapy and temozolomide (Stupp protocol), has been around for several years. ${ }^{51}$ However, the survival duration has not increased that much despite striving all the time. Treatment with BCNU wafers along with other adjuvant treatments, being a novel way to raise the OS, has been accepted by neurosurgeons only in recent years. A newly published meta-analysis showed that median survival was only 16 months, and that 1 -year and

Meta-analysis estimates, given named study is omitted

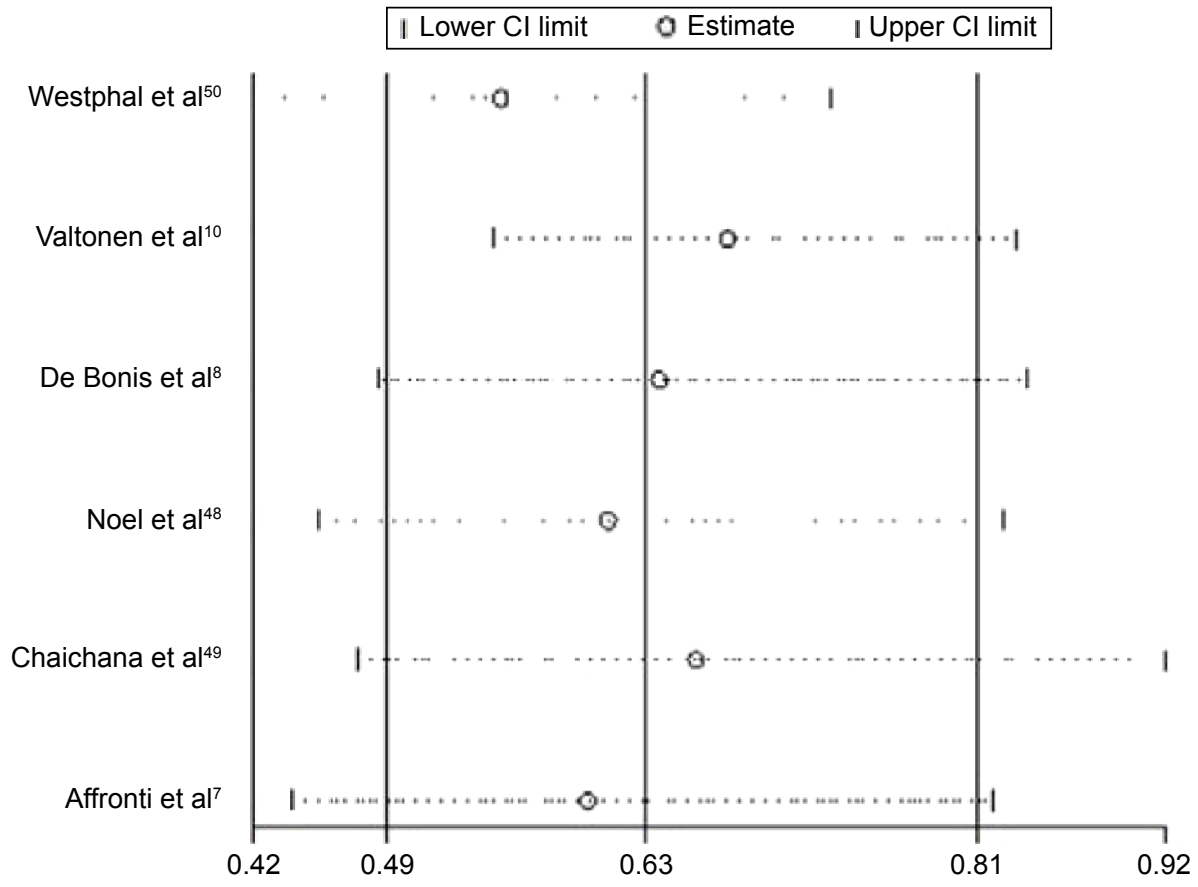

Figure 3 Sensitivity analyses of included studies.

Abbreviation: $\mathrm{Cl}$, confidence interval. 


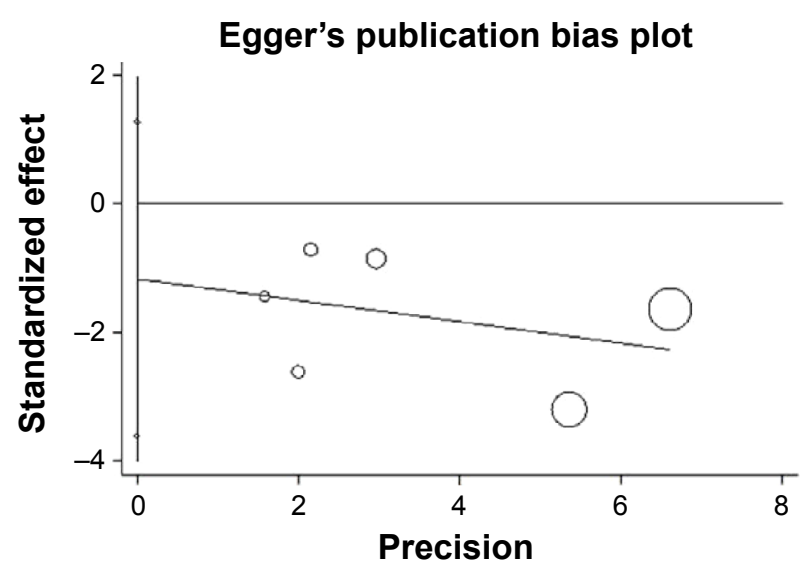

Figure 4 Egger's funnel plot for detecting publication bias.

2-year OS values were $67 \%$ and $26 \%$, respectively, in newly diagnosed HGG patients treated with carmustine wafers. ${ }^{27}$

In our study, the risk of death was decreased $37 \%$ in the newly diagnosed GBM patients treated with $\mathrm{BCNU}$ wafers. When pooling all the six studies, including RCTs and cohort studies, there was a low heterogeneity $\left(I^{2}=18.7 \%\right)$ and significant advantage $(P=0.019)$. This illustrates the important role of carmustine wafers in the treatment of newly diagnosed GBM.

Considering the high heterogeneity $(R=75.7 \%)$ of the two RCTs and combining together of cohorts, we chose a more conservative random-effects model. In the first subgroup studies, results of the two RCTs presented no statistically significant survival benefit $(\mathrm{HR}=0.51,95 \% \mathrm{CI}=0.18-1.41$; $P=0.426)$, with high heterogeneity $(P=75.7 \%)$ when pooling the HRs. The total number of patients in the studies of Westphal et al ${ }^{50}$ and Valtonen et $\mathrm{al}^{10}{ }^{10}$ were 207 and 27, respectively, which might cause the high heterogeneity. High heterogeneity might also result from the treatment design, characteristics of different patients, and techniques of neurosurgeons. In the cohort studies, we found a $41 \%$ significant risk reduction in the carmustine group $(P<0.0001)$ with low heterogeneity $\left(I^{2}=0.0 \%\right)$, strongly indicating the survival benefit of treatment with carmustine wafers.

The efficacy of BCNU wafers has been emphasized in a cohort study involving 90 old GBM patients with 44 months of follow-up. Chaichana et a ${ }^{49}$ found an obvious advantage of BCNU (HR $=0.55,95 \% \mathrm{CI}=0.38-0.79 ; P=0.007$ ). The median survival for patients treated with versus those without carmustine wafers was 8.7 months vs 5.5 months $(P=0.007)$; moreover, there was a significant survival benefit in the subgroups of patients aged 70 years and 75 years. ${ }^{49}$ Though other included cohort studies showed no statistically significant prolonged survival, they presented a slight advantage in terms of OS in patients treated with carmustine wafers. ${ }^{7,8,48}$ Considering the slower rate of occurrence of tumor regrowth in the carmustine wafer group, Hammoud et $\mathrm{al}^{52}$ carried out a study on the appearance of tumors on computed tomography and magnetic resonance imaging. A 2011 research in Italy also had faith in the treatment with carmustine wafers. ${ }^{53}$

Total tumor resection is also an important part of improving the progression-free survival and the OS time. Fluorescence-guided surgery is an effective way to help in maximal tumor resection. ${ }^{54}$

Interestingly, we found different approaches to reports of AEs from our research. In addition, other researchers also performed the same studies. A meta-analysis based on 19 researches did not suggest using carmustine wafers in GBM patients because of the high complication rate $(42.7 \%) .{ }^{21}$ However, Salvati et a ${ }^{53}$ argued that carmustine wafers appeared to be safe and feasible. Some AEs including healing abnormalities, cerebral edema, cerebrospinal fluid leaks, and intracranial infection were the most commonly reported in many studies. In some ways, good techniques should be practiced and emphasized, which might reduce the risk of the common AEs.

The cost of the treatment for patients was always an important consideration. A review of economic evaluation of BCNU wafers concluded that there was no significant advantage for patients with HGG. ${ }^{55}$ An extra 6,600 pounds need to be added for the treatment with BCNU wafers per patient. In spite of this, we appeal that the government should provide more funds to help people struggling with this misfortune.

Limitations of our study were as follows. First, there were not enough eligible studies for a meta-analysis, and the number of patients in several included studies was also too few. ${ }^{10,48}$ Second, we failed to assess the sex difference in prognosis of newly diagnosed GBM treatment. Regrettably, only Affronti et $\mathrm{al}^{7}$ showed a HR of $1.06(P=0.65)$ in males, among all our included studies. Moreover, a recent study stressed that GBM incidence seems to be male prevalent and this sex difference is tumor subtype dependent, which might also affect the OS rates..$^{56}$ Third, some data were estimated from the survival curves when the HRs and 95\% CIs were not presented. Thus, extractor bias may emerge in our study. Fourth, we just focused on the effectiveness of carmustine wafers, while the AEs and complications were not analyzed sufficiently. It might exaggerate Gliadel wafers' benefits. Finally, our results might be influenced by the potential publication bias although the Egger plots showed no proof of publication bias. Considering the above limitations, we should cautiously interpret our results. 
In conclusion, we suggest that carmustine-impregnated wafers play a significant role in improving survival when used in patients with newly diagnosed GBM. In addition, more studies, especially RCTs, should be designed for studying the new diagnosed GBM in the future.

\section{Acknowledgment}

The authors received no funding for this study.

\section{Disclosure}

The authors report no conflicts of interest in this work.

\section{References}

1. Fisher PG, Buffler PA. Malignant gliomas in 2005: where to GO from here? JAMA. 2005;293(5):615-617.

2. Kleihues P, Burger PC, Scheithauer BW. The new WHO classification of brain tumours. Brain Pathol. 1993;3(3):255-268.

3. Reardon DA, Rich JN, Friedman HS, Bigner DD. Recent advances in the treatment of malignant astrocytoma. J Clin Oncol. 2006; 24(8):1253-1265.

4. Fleming AB, Saltzman WM. Pharmacokinetics of the carmustine implant. Clin Pharmacokinet. 2002;41(6):403-419.

5. Bota DA, Desjardins A, Quinn JA, Affronti ML, Friedman HS. Interstitial chemotherapy with biodegradable BCNU (Gliadel) wafers in the treatment of malignant gliomas. Ther Clin Risk Manag. 2007; 3(5):707-715.

6. Westphal M, Hilt DC, Bortey E, et al. A phase 3 trial of local chemotherapy with biodegradable carmustine (BCNU) wafers (Gliadel wafers) in patients with primary malignant glioma. Neuro Oncol. 2003;5(2):79-88.

7. Affronti ML, Heery CR, Herndon JE 2nd, et al. Overall survival of newly diagnosed glioblastoma patients receiving carmustine wafers followed by radiation and concurrent temozolomide plus rotational multiagent chemotherapy. Cancer. 2009;115(15):3501-3511.

8. De Bonis P, Anile C, Pompucci A, et al. Safety and efficacy of Gliadel wafers for newly diagnosed and recurrent glioblastoma. Acta Neurochir (Wien). 2012;154(8):1371-1378.

9. Kleinberg L. Polifeprosan 20,3.85\% carmustine slow-release wafer in malignant glioma: evidence for role in era of standard adjuvant temozolomide. Core Evid. 2012;7:115-130.

10. Valtonen S, Timonen U, Toivanen P, et al. Interstitial chemotherapy with carmustine-loaded polymers for high-grade gliomas: a randomized double-blind study. Neurosurgery. 1997;41(1):44-48,48-49.

11. Brem H, Piantadosi S, Burger PC, et al. Placebo-controlled trial of safety and efficacy of intraoperative controlled delivery by biodegradable polymers of chemotherapy for recurrent gliomas. The Polymer-brain Tumor Treatment Group. Lancet. 1995;345(8956): 1008-1012.

12. Hart MG, Grant R, Garside R, Rogers G, Somerville M, Stein K. Chemotherapy wafers for high grade glioma. Cochrane Database Syst Rev. 2011;76(3):D7294.

13. Jadad AR, Moore RA, Carroll D, et al. Assessing the quality of reports of randomized clinical trials: is blinding necessary? Control Clin Trials. 1996;17(1):1-12.

14. Wells G, Shea B, Connell CO, Peterson J, Welch V, Losos M. The Newcastle-Ottawa Scale (NOS) for Assessing the Quality of Nonrandomised Studies in Meta-Analyses [EB/OL]. 2014.

15. Sterne J. Meta-analysis in Stata: an update collection from the Stata journal. Stata Press. 2009

16. Parmar MK, Torri V, Stewart L. Extracting summary statistics to perform meta-analyses of the published literature for survival endpoints. Stat Med. 1998;17(24):2815-2834.
17. Higgins JP, Thompson SG. Quantifying heterogeneity in a meta-analysis. Stat Med. 2002;21(11):1539-1558.

18. Higgins JP, Thompson SG, Deeks JJ, Altman DG. Measuring inconsistency in meta-analyses. BMJ. 2003;327(7414):557-560.

19. Egger M, Davey SG, Schneider M, Minder C. Bias in meta-analysis detected by a simple, graphical test. BMJ. 1997;315(7109):629-634.

20. Begg CB, Mazumdar M. Operating characteristics of a rank correlation test for publication bias. Biometrics. 1994;50(4):1088-1101.

21. Bregy A, Shah AH, Diaz MV, et al. The role of Gliadel wafers in the treatment of high-grade gliomas. Expert Rev Anticancer Ther. 2013;13(12): 1453-1461.

22. Sabel M, Giese A. Safety profile of carmustine wafers in malignant glioma: a review of controlled trials and a decade of clinical experience. Curr Med Res Opin. 2008;24(11):3239-3257.

23. Kosteljanetz M, Poulsen HS. [Chemotherapeutic wafers in treatment of malignant cerebral glioma. Assessment of a Cochrane review]. Ugeskr Laeger. 2010;172(3):214-217.

24. Lawson HC, Sampath P, Bohan E, et al. Interstitial chemotherapy for malignant gliomas: the Johns Hopkins experience. J Neurooncol. 2007;83(1):61-70.

25. Nagpal S. The role of BCNU polymer wafers (Gliadel) in the treatment of malignant glioma. Neurosurg Clin N Am. 2012;23(2):289-295.

26. Engelhard $\mathrm{HH}$. The role of interstitial BCNU chemotherapy in the treatment of malignant glioma. Surg Neurol. 2000;53(5):458-464.

27. Chowdhary SA, Ryken T, Newton HB. Survival outcomes and safety of carmustine wafers in the treatment of high-grade gliomas: a metaanalysis. J Neurooncol. 2015;122(2):367-382.

28. Wait SD, Prabhu RS, Burri SH, Atkins TG, Asher AL. Polymeric drug delivery for the treatment of glioblastoma. Neuro Oncol. 2015;17(suppl2): i9-i23.

29. Venur VA, Peereboom DM, Ahluwalia MS. Current medical treatment of glioblastoma. Cancer Treat Res. 2015;163:103-115.

30. Menei P, Metellus P, Parot-Schinkel E, et al; Neuro-oncology Club of the French Society of Neurosurgery. Biodegradable carmustine wafers (Gliadel) alone or in combination with chemoradiotherapy: the French experience. Ann Surg Oncol. 2010;17(7):1740-1746.

31. McGirt MJ, Than KD, Weingart JD, et al. Gliadel (BCNU) wafer plus concomitant temozolomide therapy after primary resection of glioblastoma multiforme. J Neurosurg. 2009;110(3):583-588.

32. Lechapt-Zalcman E, Levallet G, Dugué AE, et al. O(6) -methylguanineDNA methyltransferase (MGMT) promoter methylation and low MGMT-encoded protein expression as prognostic markers in glioblastoma patients treated with biodegradable carmustine wafer implants after initial surgery followed by radiotherapy with concomitant and adjuvant temozolomide. Cancer. 2012;118(18):4545-4554.

33. Catalán-Uribarrena G, Bilbao-Barandica G, Pomposo-Gaztelu I, et al. Prognostic factors and survival in a prospective cohort of patients with high-grade glioma treated with carmustine wafers or temozolomide on an intention-to-treat basis. Acta Neurochir (Wien). 2012; 154(2):211-222

34. Weingart J, Grossman SA, Carson KA, et al. Phase I trial of polifeprosan 20 with carmustine implant plus continuous infusion of intravenous O6-benzylguanine in adults with recurrent malignant glioma: new approaches to brain tumor therapy CNS consortium trial. J Clin Oncol. 2007;25(4):399-404.

35. Gutenberg A, Bock HC, Bruck W, et al. MGMT promoter methylation status and prognosis of patients with primary or recurrent glioblastoma treated with carmustine wafers. Br J Neurosurg. 2013;27(6): $772-778$.

36. Metellus P, Coulibaly B, Nanni I, et al. Prognostic impact of O6-methylguanine-DNA methyltransferase silencing in patients with recurrent glioblastoma multiforme who undergo surgery and carmustine wafer implantation: a prospective patient cohort. Cancer. 2009;115(20):4783-4794

37. Ko AL, Fink KR, Stelzer KM, Silbergeld DL. Safety and efficacy of concomitant chemotherapeutic wafers and iodine- 125 seeds for recurrent glioblastoma. Surg Neurol Int. 2012;3:137. 
38. Smith KA, Ashby LS, Gonzalez LF, et al. Prospective trial of grosstotal resection with Gliadel wafers followed by early postoperative Gamma knife radiosurgery and conformal fractionated radiotherapy as the initial treatment for patients with radiographically suspected, newly diagnosed glioblastoma multiforme. J Neurosurg. 2008;109(suppl): 106-117.

39. McPherson CM, Gerena-Lewis M, Breneman JC, Warnick RE. Results of phase I study of a multi-modality treatment for newly diagnosed glioblastoma multiforme using local implantation of concurrent BCNU wafers and permanent I-125 seeds followed by fractionated radiation and temozolomide chemotherapy. J Neurooncol. 2012;108(3):521-525.

40. Miglierini P, Bouchekoua M, Rousseau B, Hieu PD, Malhaire JP, Pradier O. Impact of the per-operatory application of GLIADEL wafers (BCNU, carmustine) in combination with temozolomide and radiotherapy in patients with glioblastoma multiforme: efficacy and toxicity. Clin Neurol Neurosurg. 2012;114(9):1222-1225.

41. Duntze J, Litré CF, Eap C, et al. Implanted carmustine wafers followed by concomitant radiochemotherapy to treat newly diagnosed malignant gliomas: prospective, observational, multicenter study on 92 cases. Ann Surg Oncol. 2013;20(6):2065-2072.

42. Kleinberg LR, Weingart J, Burger P, et al. Clinical course and pathologic findings after Gliadel and radiotherapy for newly diagnosed malignant glioma: implications for patient management. Cancer Invest. 2004;22(1):1-9.

43. Attenello FJ, Mukherjee D, Datoo G, et al. Use of Gliadel (BCNU) wafer in the surgical treatment of malignant glioma: a 10-year institutional experience. Ann Surg Oncol. 2008;15(10):2887-2893.

44. Giese A, Kucinski T, Knopp U, et al. Pattern of recurrence following local chemotherapy with biodegradable carmustine (BCNU) implants in patients with glioblastoma. J Neurooncol. 2004;66(3): 351-360.

45. Stummer W, van den Bent MJ, Westphal M. Cytoreductive surgery of glioblastoma as the key to successful adjuvant therapies: new arguments in an old discussion. Acta Neurochir (Wien). 2011;153(6): 1211-1218.

46. Samis Zella MA, Wallocha M, Slotty PJ, et al. Evaluation of post-operative complications associated with repeat resection and BCNU wafer implantation in recurrent glioblastoma. Acta Neurochir (Wien). 2014;156(2): 313-323.
47. Subach BR, Witham TF, Kondziolka D, Lunsford LD, Bozik M, Schiff D. Morbidity and survival after 1,3-bis(2-chloroethyl)-1-nitrosourea wafer implantation for recurrent glioblastoma: a retrospective case-matched cohort series. Neurosurgery. 1999;45(1):17-22,22-23.

48. Noel G, Schott R, Froelich S, et al. Retrospective comparison of chemoradiotherapy followed by adjuvant chemotherapy, with or without prior gliadel implantation (carmustine) after initial surgery in patients with newly diagnosed high-grade gliomas. Int J Radiat Oncol Biol Phys. 2012;82(2):749-755.

49. Chaichana KL, Zaidi H, Pendleton C, et al. The efficacy of carmustine wafers for older patients with glioblastoma multiforme: prolonging survival. Neurol Res. 2011;33(7):759-764.

50. Westphal M, Ram Z, Riddle V, Hilt D, Bortey E. Gliadel wafer in initial surgery for malignant glioma: long-term follow-up of a multicenter controlled trial. Acta Neurochir (Wien). 2006;148(3):269-275.

51. Stupp R, Mason WP, van den Bent MJ, et al; European Organisation for Research and Treatment of Cancer Brain Tumor and Radiotherapy Groups, National Cancer Institute of Canada Clinical Trials Group. Radiotherapy plus concomitant and adjuvant temozolomide for glioblastoma. N Engl J Med. 2005;352(10):987-996.

52. Hammoud DA, Belden CJ, Ho AC, et al. The surgical bed after BCNU polymer wafer placement for recurrent glioma: serial assessment on CT and MR imaging. AJR Am J Roentgenol. 2003;180(5):1469-1475.

53. Salvati M, D'Elia A, Frati A, Brogna C, Santoro A, Delfini R. Safety and feasibility of the adjunct of local chemotherapy with biodegradable carmustine (BCNU) wafers to the standard multimodal approach to high grade gliomas at first diagnosis. J Neurosurg Sci. 2011;55(1):1-6.

54. Stummer W, Pichlmeier U, Meinel T, Wiestler OD, Zanella F, Reulen HJ. Fluorescence-guided surgery with 5-aminolevulinic acid for resection of malignant glioma: a randomised controlled multicentre phase III trial. Lancet Oncol. 2006;7(5):392-401.

55. Garside R, Pitt M, Anderson R, et al. The effectiveness and cost-effectiveness of carmustine implants and temozolomide for the treatment of newly diagnosed high-grade glioma: a systematic review and economic evaluation. Health Technol Assess. 2007;11(45):221.

56. Sun T, Warrington NM, Luo J, et al. Sexually dimorphic RB inactivation underlies mesenchymal glioblastoma prevalence in males. J Clin Invest. 2014;124(9):4123-4133.
Drug Design, Development and Therapy

\section{Publish your work in this journal}

Drug Design, Development and Therapy is an international, peerreviewed open-access journal that spans the spectrum of drug design and development through to clinical applications. Clinical outcomes, patient safety, and programs for the development and effective, safe, and sustained use of medicines are a feature of the journal, which

\section{Dovepress}

has also been accepted for indexing on PubMed Central. The manuscript management system is completely online and includes a very quick and fair peer-review system, which is all easy to use. Visit http://www.dovepress.com/testimonials.php to read real quotes from published authors. 